\title{
Two new ripidiine species in Dominican amber with evidence of aggregative behaviour of males "frozen" in the fossil record (Coleoptera: Ripiphoridae)
}

\author{
JAN BATELKA ${ }^{1}$, Michael S. ENGEL ${ }^{2}$, ZAChaRY H. FALIN ${ }^{2}$ and JAKUB PROKOP ${ }^{3}$ \\ ${ }^{1}$ Nad vodovodem 16, CZ-100 00, Praha 10, Czech Republic; e-mail: janbat@centrum.cz \\ ${ }^{2}$ Divison of Entomology (Paleoentomology), Natural History Museum, and Department of Ecology \& Evolutionary Biology, \\ 1501 Crestline Drive - Suite 140, University of Kansas, Lawrence, Kansas 66049-2811, USA; e-mail: msengel@ku.edu \\ ${ }^{3}$ Department of Zoology, Faculty of Science, Charles University in Prague, Viničná 7, 12844 Praha 2, Czech Republic; \\ e-mail: jprokop@natur.cuni.cz
}

Key words. Taxonomy, Coleoptera, Ripiphoridae, Ripidiinae, Neorrhipidius, Quasipirhidius, new species, Tertiary, Miocene, Dominican amber, Central America, paleoethology, aggregative behaviour

\begin{abstract}
Ten amber inclusions of male Ripidiinae (Coleoptera: Ripiphoridae) are reported from Early Miocene deposits of the Dominican Republic and compared with extant species of Neorrhipidius Viana, 1958 from Argentina and Paraguay and Quasipirhidius Zaragoza Caballero, 1991 from Mexico. Neorrhipidius seicherti sp. n. and Quasipirhidius luzziae sp. n. are described and illustrated. Both species are characterised by 11-segmented antennae with eight distal antennomeres uniflabellate, mouthparts reduced to maxillary palpi represented by long styli with fused basal palpomeres, by metathoracic wings without crossveins and tarsal formula of 5-5-4. Neorrhipidius seicherti sp. n. differs from Quasipirhidius luzziae sp. n. by the presence of postocular ommatidia and by the shape of metascutellum. The distribution of fossil and extant Ripidiinae in Central America is briefly discussed. Furthermore, the frequent occurrence of Quasipirhidius luzziae sp. n. in amber as syninclusions suggests possibly unique synchronisation of emergence unknown in extant taxa or more likely intraspecific aggregative behaviour by males prior to mating with receptive females.
\end{abstract}

\section{INTRODUCTION}

The island Hispaniola is famous for its rich fossiliferous amber deposits, with biological inclusions preserved in a clear light-orange to yellow resin that often has been popularized and the focus of innumerable scientific studies (e.g., Grimaldi, 1996; Poinar \& Poinar, 1999; $\mathrm{Wu}, 1997)$. A catalogue of described insect taxa in Dominican amber was provided by Arillo \& Ortuño (2005), but is already somewhat out of date owing to the description of various additional species. The amber putatively originated from the extinct tree Hymenaea protera Poinar, 1991 (Leguminoseae) that apparently was widely distributed in Central America. Despite earlier confusion regarding the age of the amber-bearing deposits (e.g., Lambert et al., 1985; Poinar, 1992), the Dominican amber is soundly of Early Miocene (Burdigalian) age (Grimaldi, 1995; Iturralde-Vinent \& MacPhee, 1996, 1999; Grimaldi \& Engel, 2005).

Ripiphorid beetles were first recorded and figured from Dominican amber by Poinar (1992). Subsequently, a triple syninclusion and another isolated male of the same or a similar species were figured by Wu (1997). The possible systematic placement of these records within Ripidiinae was mentioned by Kaupp et al. (2001). Although Poinar (1992) and Poinar \& Poinar (1999) associated their figured specimen with possible parasitism on Hymenoptera (i.e., subfamily Ripiphorinae), clearly it belongs to Ripidiinae owing to the globular head with holoptic compound eyes composed of large, protruding ommatidia, shortened elytra, atrophied mouthparts, and uniflabellate antennae.

Ripidiinae comprises about 20 extant and fossil genera, grouped in two tribes, Ripidiini and Eorhipidiini, although many new genera await description and some have been synonymised recently (Batelka, 2009; Batelka \& Hájek, 2010). Owing to the extreme sexual dimorphism in these species (winged males with flabellate antennae vs. larviform females with simple or even extremely reduced antennae), most genera are known exclusively from the winged males which are difficult to associate with females captured in isolation.

Fossil Ripidiinae, represented only by males of Ripidiini, are known from various amber deposits. The extinct genus and species Paleoripiphorus deploegi Perrichot, Nel et Néraudeau, 2004 from French Albo-Cenomanian amber was originally described in Ripiphorinae (Perrichot et al., 2004) because of its biflabellate antennae, but subsequently transferred to Ripidiinae owing to its globular head with enlarged, roughly-faceted compound eyes, atrophied mouthparts, and some other features (Batelka et al., 2006; Falin \& Engel, 2010). In addition, the latest Albian "Myodites" burmiticus Cockerell, 1917 has been transferred to a new genus Cretaceoripidius Falin \& Engel, 2010 in Ripidiinae (Falin \& Engel, 2010). Two genera are reported from mid-Eocene Baltic amber: the extint Pauroripidius Kaupp et Nagel in Kaupp et al., 
2001, and the extant Ripidius Thunberg, 1806. The latter genus is also reported in subfossil copal (origin and age unknown) (Kaupp et al., 2001).

The males studied and described herein were identified as members of Quasipirhidius Zaragoza Caballero, 1991 and Neorrhipidius Viana, 1958, noting however that both of these genera may prove eventually to be merely derived forms of Pirhidius Besuchet, 1957 (Falin, in prep.). The fossil inclusions are remarkably similar to extant species of Quasipirhidius from Mexico and Neorrhipidius from Argentina and Paraguay, respectively.

\section{MATERIAL AND METHODS}

Many ripiphorid specimens from Dominican amber similar to those shown in Poinar (1992), Wu (1997) and Grimaldi \& Engel (2005) have been available for purchase through internet dealers over the last several years. The first author purchased seven pieces of Dominican amber between 2006 and 2010, six with a single male ripiphorid in each and one piece with three males as a syninclusion.

The figures of the type specimens were prepared using a Nikon D1x digital camera attached to an Infinity K-2 longdistance microscopic lens or by an Olympus Camedia C-5060 digital camera attached to an Olympus SZX-9 binocular stereomicroscope.

Studied material of amber insect inclusions is housed in the following collections: SEMC - Fossil Insect Collection, Division of Entomology, University of Kansas Natural History Museum, Lawrence, Kansas, USA; SMNS - "Jan Batelka Amber Collection (JBAC)" deposited in Staatliches Museum für Naturkunde, Stuttgart, Germany (Günter Bechly).

\section{Terminology}

For the descriptions and alphabetic markings of thoracic structures we follow the terminology of Besuchet (1957) and Zaragoza Caballero (1991): a - pronotal disc, b - mesonotal disc, c - mesonotal scutellum (not developed in our specimens), $\mathrm{d}$ - metaprescutum, e - metascutum, f - metascutellum, g postscutellum. However, we noted at least one discrepancy in usage of this terminology in those drawings by Zaragoza Caballero (1991); his so-called "c = escutelo mesotorácico" in Quasirhipidius and Quasipirhidius (p. 484, Figs 4, 6 and 8) is depicted in all three cases as a part of the metaprescutum, i.e., completely separated from the mesonotal disc. Because the "mesonotal scutellum" cannot be part of the metanotum we refer to this structure (detectable in both newly described fossil species) as "box of metaprescutum".

A further structure called by the same author " $\mathrm{h}=$ posnoto" is not visible in our specimens (possibly covered by the elytra), however it seems to be also just a "sub-region" of the metaprescutum and probably does not deserve any independent term.

\section{SYSTEMATIC PART}

\section{Subfamily Ripidiinae Gerstaecker, 1855}

\section{Tribe Ripidiini Gerstaecker, 1855}

\section{Systematics of the New World Ripidiini}

When describing the extant genera Quasirhipidius and Quasipirhidius from Mexico, Zaragoza Caballero (1991) omitted in his diagnoses and key to American Ripidiinae the existence of the South American genus Neorrhipidius, with three extant species from Argentina and Paraguay (Viana, 1958) (the generic name is not a homonym of the
Australian genus Neorhipidius Riek, 1955 written with single "r"). Species of Neorrhipidius (for the type species of the genus see Figs 18-25) vary in number of postocular ommatidia (one, two and four) but the genus is otherwise exceptionally similar to Quasirhipidius with three postocular ommatidia and to Quasipirhidius (for the type species of the genus see Figs 14-17) in which these ommatidia are missing. Unpublished studies by one of us (Falin, in prep.) suggest that these genera are themselves merely derived forms of Pirhidius, a genus described from Brasilia and recorded also from U.S.A. (Florida) (Falin, 2001). They are characterized by 11-segmented antennae with eight distal antennomeres uniflabellate (number of antennal segments is reduced in Blattivorus Chobaut, 1891, Falsorhipidius Pic, 1947 and Pauroripidius Kaupp \& Nagel, 2001 and reduced and biflabellate in Paleoripiphorus), by mouthparts with maxillary palpi formed as long styli with fused basal palpomeres (maxillary palpi are reduced to an unpaired knob-like stylus in Pseudorhipidius Chobaut, 1894, Rhipidioides Riek, 1955 and Blattivorus or the styli are long with basal palpomeres discrete in Ripidius), by metathoracic wings without crossveins (crossveins and more complex venation are present in the Australian genera Neonephrites Riek, 1955, Rhipidioides, and Riekella Selander, 1957), and by the 5-5-4 tarsal formula (4-4-4 in Falsorhipidius). The Australian genera Neorhipidius Riek, 1955 and Paranephrites Riek, 1955 are known only from females and cannot be used for differential diagnosis.

The form of the maxillary palpi, the shape of structures in the metanotum and the presence or absence of postocular ommatidia have been used as generic characters in Neorrhipidius, Pirhidius, Quasipirhidius and Quasirhipidius (cf. Viana, 1958; Zaragoza Caballero, 1991). For the shape of the metanotal structures of extant representatives see Figs 24, 26-30. However, apparent continuous transition of these characters, i.e., from zero to four postocular ommatidia, from almost simple metaprescutum to metaprescutum with sharply defined "box" or even with other features (i.e., so called "posnoto"), and maxillary palpi with one or two fused basal articles, indicate that their usage for generic discrimination in this group should be re-evaluated (Falin, in prep.). All these genera could be synonymous and they are in need of revision.

For the time being and for the purposes of this contribution we follow current usage, as well as Viana (1958) and Zaragoza Caballero (1991), and consider the genera Neorrhipidius and Quasipirhidius as valid.

\section{Genus Quasipirhidius Zaragoza Caballero, 1991 Quasipirhidius luzziae sp. n.}

(Figs 1-13, 31-32)

\section{Diagnosis (male)}

General body form and size typical of Ripidiini, head without postocular ommatidia, maxillary palpi each consisting of two palpomeres, basal palpomeres fused, antennae with 11 antennomeres, mesothoracic scutellum absent, metathoracic prescutum with a well defined "box". The widest part of metascutellum is $2.6 \times$ wider 


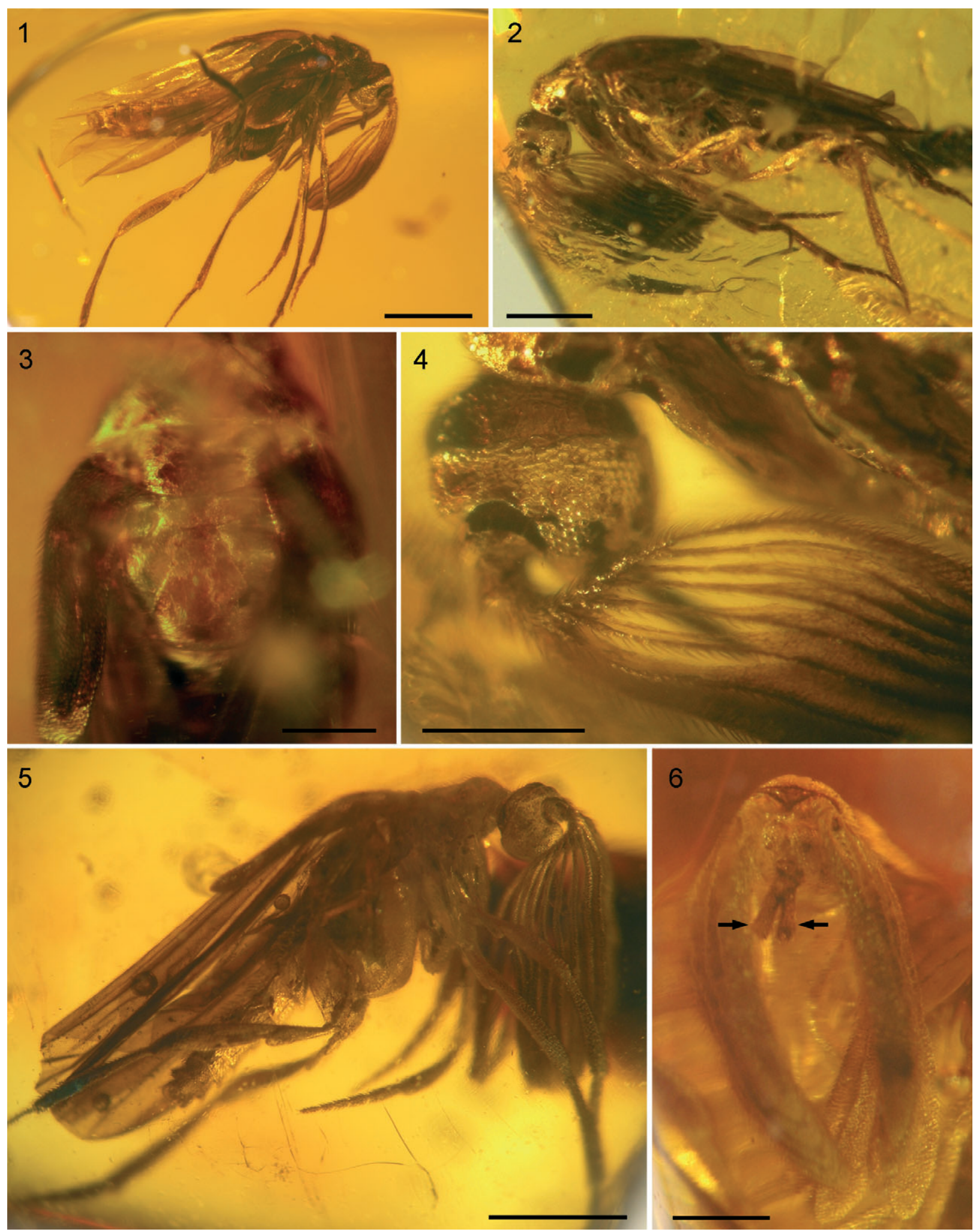

Figs 1-6. Quasipirhidius luzziae sp. n. 1 - holotype No. DR-022, habitus (scale bar $1 \mathrm{~mm}$ ). 2-4, paratype 1 No. DA01/DA550003: 2 - habitus (scale bar $1 \mathrm{~mm}$ ); 3 - pronotal disc, mesonotal disc and metanotum (scale bar $0.5 \mathrm{~mm}$ ); 4 - detail of head (scale bar $0.5 \mathrm{~mm}$ ). 5-6, paratype 2 No. DA05/01950: 5 - habitus (scale bar $1 \mathrm{~mm}$ ); 6 - head, antennae and palpomeres (arrows to maxillary palpi with fused styli) (scale bar $0.5 \mathrm{~mm}$ ).

than its base contiguous to metaprescutum. Body nearly unicolorous brown; palpi, coxae, trochanters, femora, and abdomen slightly lighter in color than remainder of body; antennomeres I-III and basal one-quarter to one-fifth of antennal rami also paler. Elytra smokey brown, translucent, appearing to have whitish apices. Metathoracic wings with venation strongly reduced typical of subfamily, without crossveins. 


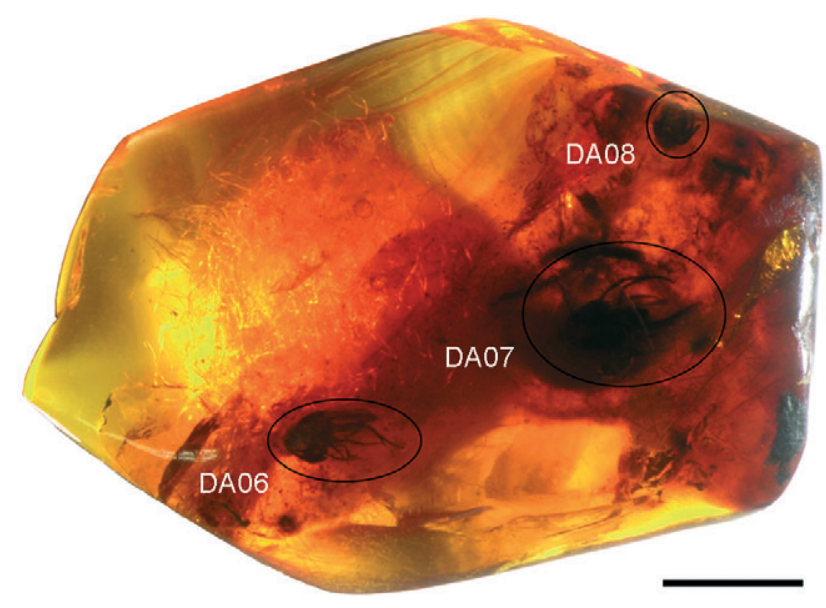

Fig. 7. Quasipirhidius luzziae sp. n., paratype specimens 3-5 No. DA06-08/01491, piece of amber with triple syninclusion, type specimens in circles (scale bar $5 \mathrm{~mm}$ ).

\section{Description}

Male: Body length 3.1-4.4 mm from tip of fully extended abdomen to bases of antennae. Head small, typical of Ripidiini. Vertex very slightly pointed at transition to occiput, integumental luster difficult to gauge, surface densely punctured, appearing sub-granular. Erect whitish setae present on head, longest on occiput, no visible setae on compound eyes. Compound eyes large, coarsely faceted, weakly contiguous dorsally and between antennal bases and maxillary palpi, strongly contiguous ventrally; ventral one-third of compound eyes expanded; lateral margins of compound eyes nearly straight. Postocular ommatidia absent. Maxillary palpi arising from ventral edge of a small triangular sclerite; palpi consisting of two palpomeres, basal palpomeres fused, approximately equal in width and length, approximately one-half length of apical palpomeres; apical palpomeres cylindrical, attached directly (not obliquely) to basal palpomere, tapered apically. Antennae typical of males of the tribe, consisting of 11 antennomeres; basal antennomere short, broad, assymetrically navicular. Antennomere II irregularly toroidal; III small, half length of antennomere II, tightly articulated to antennomere IV. Antennomere IV through $\mathrm{X}$ with internally facing rami, base of each successive antennomere becoming only very gradually longer, exterior surface of antennomere bases IV-VIII impressed longitudinally giving the appearance of two small lobes opposite the ramus. Antennomere XI expanded, similar in shape to rami of previous antennomeres. Antennae constructed such that rami VI-X appear nearly equal in lenth, rami V and IV successively subequal; antennomere XI approximately five times longer than bases of antennomeres IV-X combined. Pronotum slightly deformed but appearing typically bell-shaped if somewhat foreshortened, humeral angles prominent, extending beyond posterior margin, posterior margins nearly straight, anterior margin broadly, shallowly excavate; pronotum without lateral margin. Two large and moderately strong impressions on pronotal disc, one to either side of midline (typical in many genera of Ripidiini). Punctation and setation of pronotum similar to that of vertex. Mesonotum roughly quadrate from above, with punctation and setation similar to that of vertex and pronotum. Mesonotal disc very slightly convex with a poorly defined medial impression anteriorly. Mesonotum without defined scutellum, posterior margin very gently convex. Metanotal integument slightly less densely, more weakly punctured than pro- and mesonotum. Metaprescutum with a "box" defined posteriorly by a bisinuous impressed sulcus, laterally by indistinct longitudinal impressions. Metascutum incompletely separated from the lateral aspects of prescutum by apices of bisinuous sulcus, lateral aspects deeply recessed; metascutellum convex, clearly delineated by a pair of oblique sulci that nearly converge anteriorly, its widest part is $2.6 \times$ wider than its base contiguous to metaprescutum; postscutellum

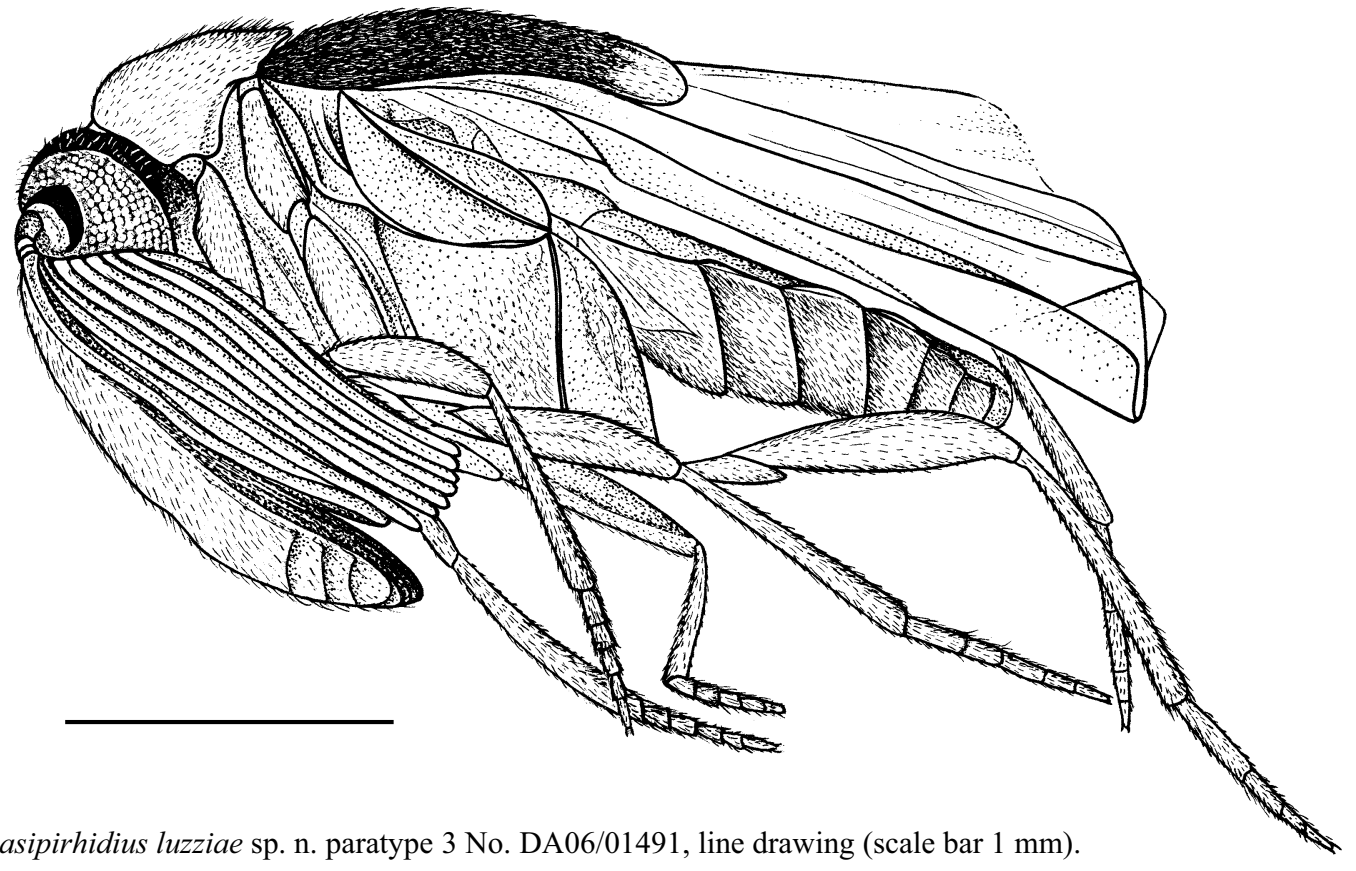

Fig. 8. Quasipirhidius luzziae sp. n. paratype 3 No. DA06/01491, line drawing (scale bar $1 \mathrm{~mm}$ ). 

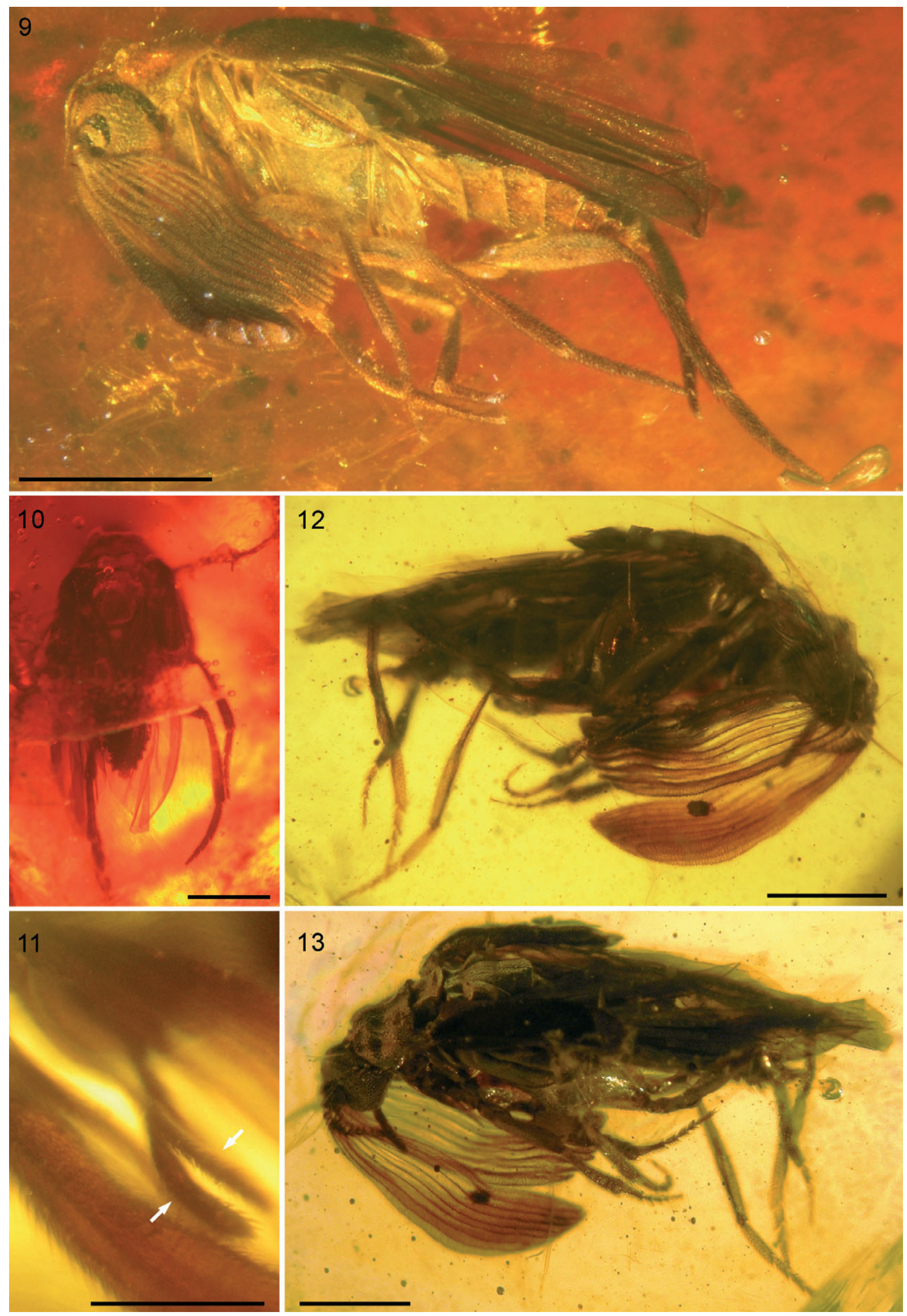

Figs 9-13. Quasipirhidius luzziae sp. n. 9 - paratype 3 No. DA06/01491, habitus (scale bar $1 \mathrm{~mm}$ ). 10 - paratype 4 No. DA07/01491, dorsal view (scale bar $1 \mathrm{~mm}$ ). 11-13, paratype 6 No. DA02/DR4065: 11 - palpomeres (arrows) (scale bar $0.5 \mathrm{~mm}$ ); 12 - habitus right side; 13 - habitus left side (scale bars $1 \mathrm{~mm}$ ). 


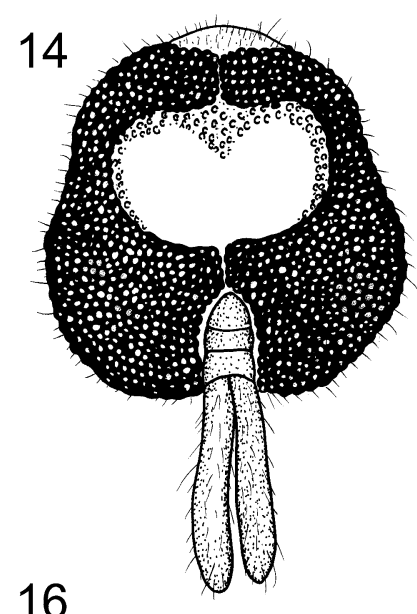

16

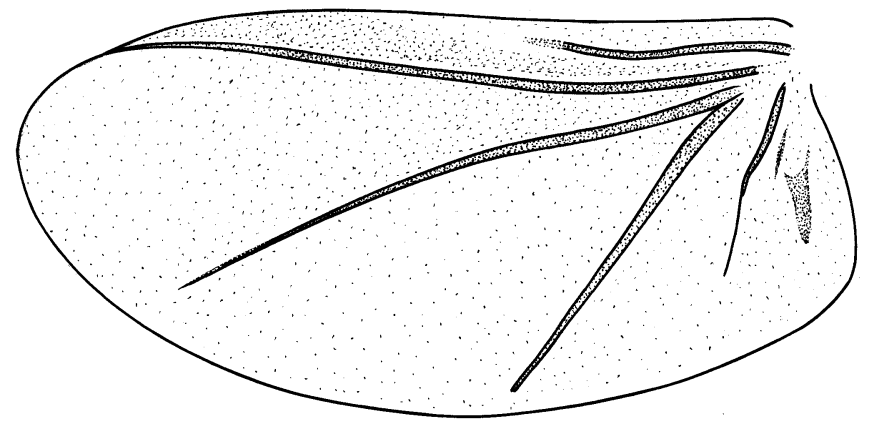

15
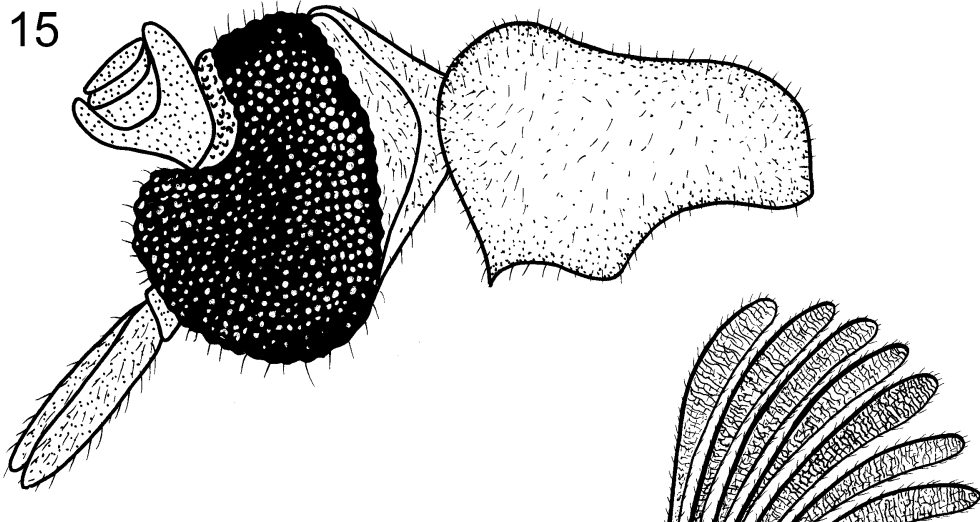

17

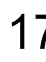

Figs 14-17. Quasipirhidius besucheti Zaragoza Caballero, 1991. 14 - head frontal view; 15 - head and thorax lateral view; 16 metathoracic wing; 17 - head, antenna and pronotal disc dorsal view. Redrawn from Zaragoza Caballero, 1991.

mostly obscured by posterior margin of metascutellum, appearing as a narrow and recessed band. Lateral and ventral aspects of thorax typical of tribe, less well sclerotized than dorsal aspects (in this regard essentially similar to the extant species Pirhidius beaumonti Besuchet, 1957); integument weakly and sparsely punctate; setae indiscernible. Legs typical: coxae, trochanters, and femora smooth and shining, the latter relatively more punctate; tibiae darker, more strongly punctate; setae difficult to discern, appearing as suberect, short, and coarse on tibiae and tarsi; apices of tibiae without spurs; tarsi 5-5-4, all segments more or less cylindrical, progressively tapering in diameter, more pronouncedly so in proand metatarsomeres; pretarsal claws small, simple. Elytra thin, translucent, leathery; integumental punctation and setation similar to remainder of dorsum; widely separated, about one-third longer than metathorax when closed; slightly deformed in preservation, narrow, lateral margins appearing nearly parallel; apices gently rounded and curled. Hind wings transparent and highly reflective but covered with microsetae, giving a slightly fuscous appearance. Abdomen typical of tribe, eight (II-IX) visible tergites, seven (III-IX) visible ventrites (typically abdominal segment IX closely associated with segment VIII and difficult to separate; in this case it is strongly everted); weakly sclerotized with weak punctation and indiscernible setation. Abdominal segment IX roughly circular in longitudinal view; dorsal aspect of segment IX with straight, parallel anterior and posterior margins; ventral aspect with posterior margin deeply excavate. Tegmen hidden within abdominal segment IX; apices of gonoforceps visible, well-sclerotized, appearing as nearly

TABLE 1. Variability of Quasipirhidius luzziae sp. n. and Neorrhipidius seicherti sp. n. Measurements in millimeters; NM = not measurable; torso of Do-5738 (DA08) and Do-5739 (DA09) are excluded.

\begin{tabular}{|c|c|c|c|c|c|}
\hline & length of body & height of head & length of XI antennomere & length of elytra & length of metatibia + metatarsus \\
\hline \multicolumn{6}{|l|}{ Q. luzziae sp. n. } \\
\hline DR-022 & 3.5 & 0.6 & 1.5 & 1.3 & 1.6 \\
\hline Do-5733 (DA01) & 4.2 & 0.6 & 1.6 & 1.4 & 1.8 \\
\hline Do-5735 (DA02) & 4.4 & 0.7 & 2.0 & 1.7 & 2.5 \\
\hline Do-5737 (DA05) & 3.5 & 0.7 & 1.6 & 1.8 & 2.6 \\
\hline Do-5738 (DA06) & 3.1 & 0.6 & 1.1 & 1.3 & 1.6 \\
\hline Do-5738 (DA07) & NM & NM & NM & 1.6 & 1.9 \\
\hline \multicolumn{6}{|l|}{ N. seicherti sp. n. } \\
\hline Do-5734 (DA03) & 3.3 & 0.6 & 1.4 & 1.3 & 1.4 \\
\hline Do-5736 (DA04) & 4.0 & 0.6 & 1.3 & 1.5 & 1.9 \\
\hline
\end{tabular}




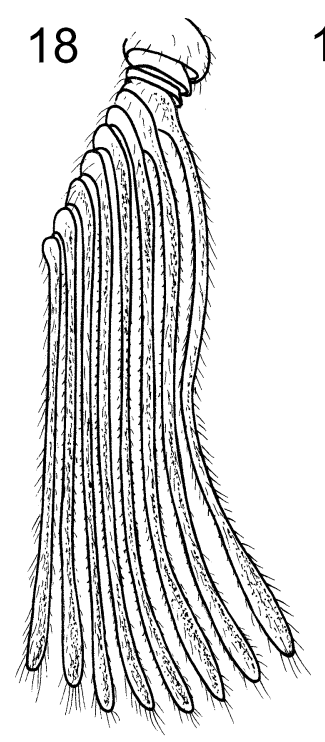

19
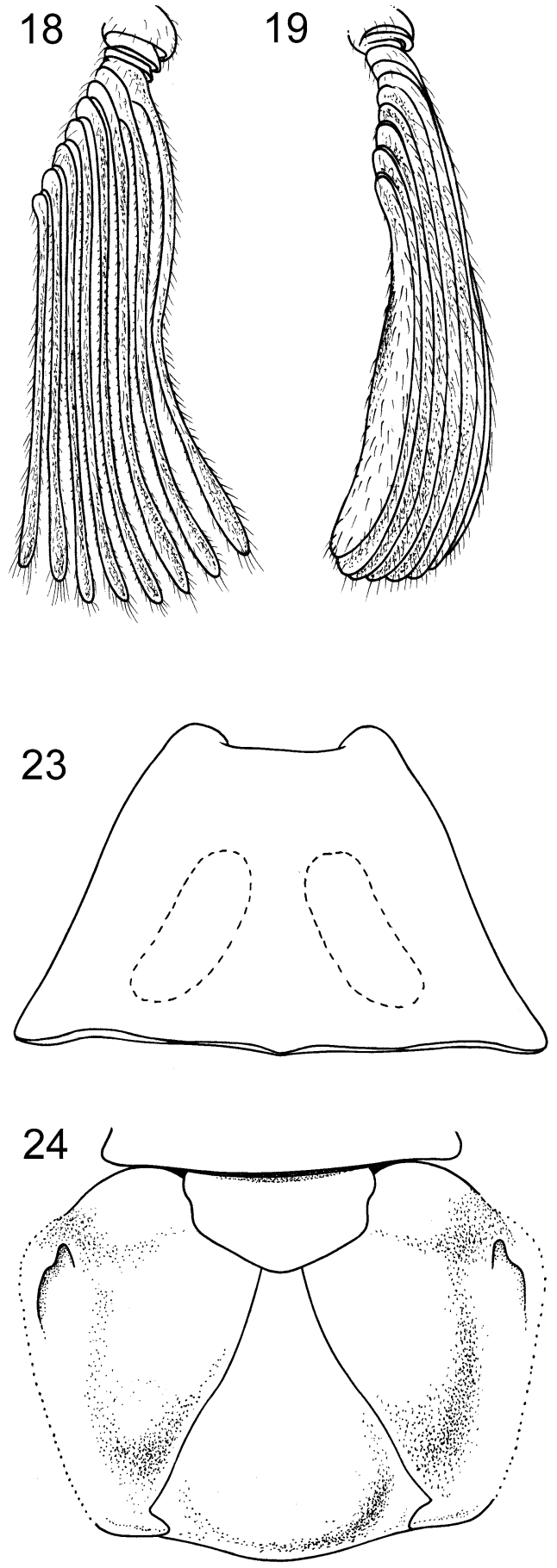

20
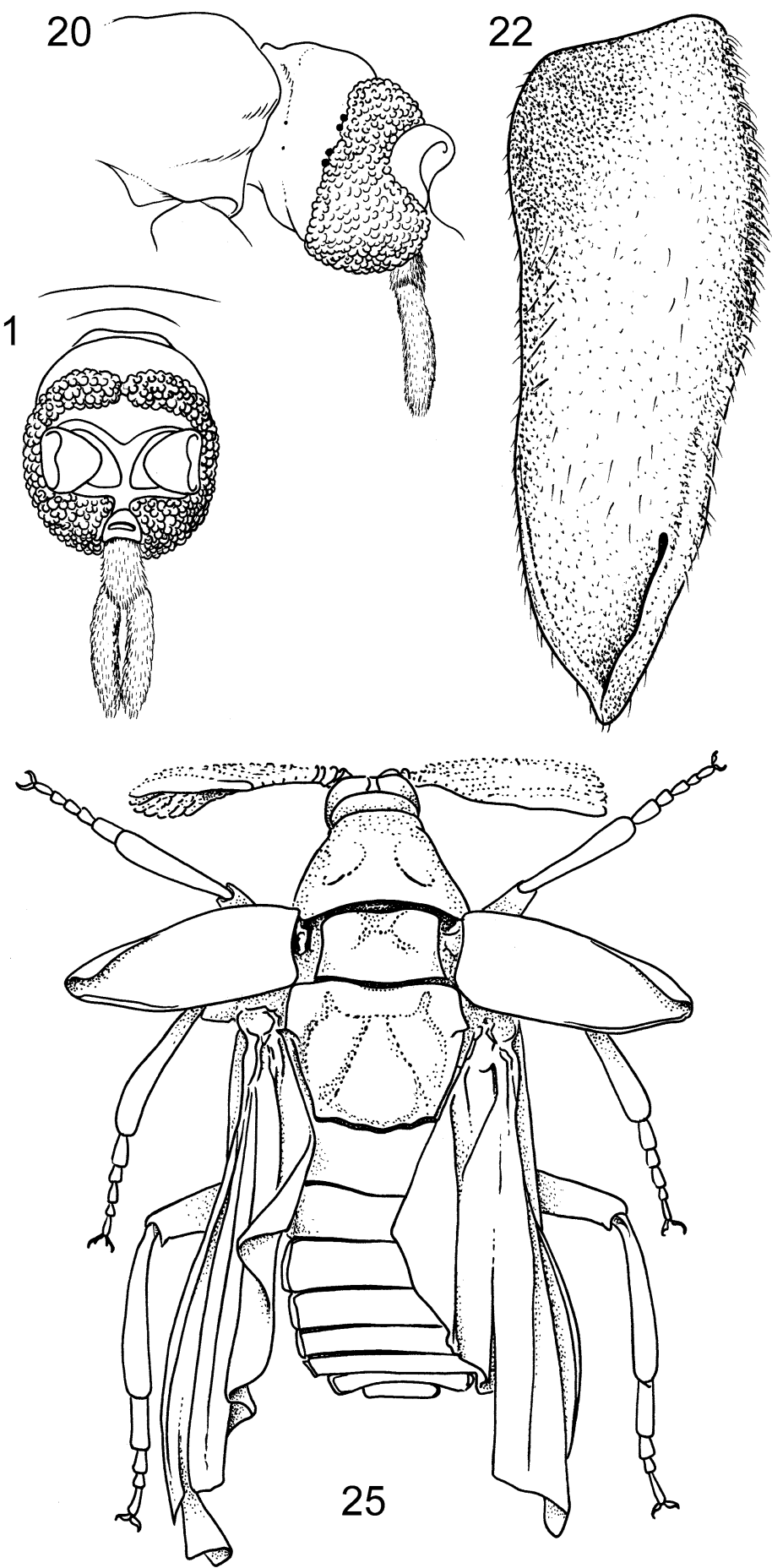

Figs 18-25. Neorrhipidius cordobensis Viana, 1958. 18-19 - antenna; 20-21 - head lateral and frontal view; 22 - elytron; 23 pronotal disc; 24 - metanotum dorsal view; 25 - habitus. Redrawn from Viana, 1958.

symmetrical nodes or bumps. Apex of median lobe visible, light in color, appearing as a simple, straight tube with an obliquely beveled posterior tip. Measurements in Table 1.

Female: Unknown.

Immature stages and host: Unknown.

Holotype: No. SEMC DR-022, male, Dominican amber. Paratype 1. No. SMNS-Do-5733 (JBAC DA01/DA550003), Dominican amber. Original size of amber piece was $24 \times 18$ mm. Location: Region near Santiago. Paratype 2. No. SMNS-
Do-5737 (JBAC DA05/01950), male, Dominican amber. Precise mine is not known. Paratypes 3-5. No. SMNS-Do-5738 (JBAC DA06-08/01491), male triple syninclusion. The paratype 3 (DA06/01491) is completely preserved, visible from the left lateral side; paratype 4 (DA07/01491) is completely preserved, visible from dorsal side with head and antennae hidden beneath the body; paratype 5 (DA08/01491) is only partially preserved, pronotum and thorax with elytra visible dorsally, abdomen and wings were destroyed by grinding. Dominican amber. Precise mine is not known. In the same piece of amber there are one small, poorly visible, wood-boring beetle close to paratype 4 

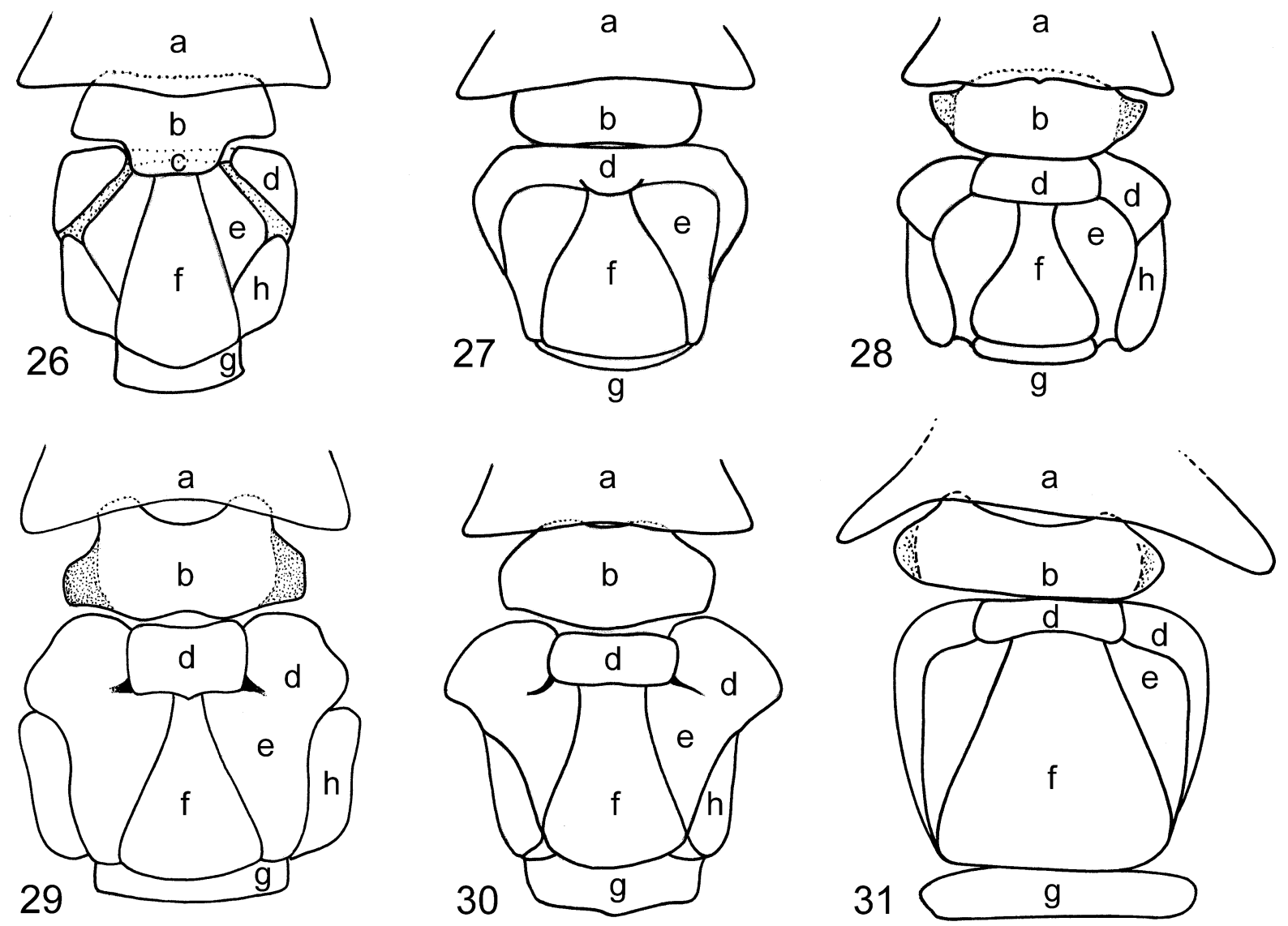

Figs 26-31. Line drawings of metanotal structures in dorsal view. 26 - Ripidius mexicanus Zaragoza Caballero, 1984; 27 - Pirhidius beaumonti Besuchet, 1957; 28 - Quasirhipidius selanderi Zaragoza Caballero, 1991; 29 - Quasipirhidius besucheti Zaragoza Caballero, 1991; 30 - Quasipirhidius rieki Zaragoza Caballero, 1991; 31 - Quasipirhidius luzziae sp. n. paratype specimen 5 No.DA08/01491. Lettering: a - pronotal disc, $\mathrm{b}$ - mesonotal disc, $\mathrm{c}$ - mesonotal scutellum, $\mathrm{d}$ - metaprescutum, $\mathrm{e}$ - metascutum, $\mathrm{f}-$ metascutellum, $\mathrm{g}$ - postscutellum, $\mathrm{h}$ - postnotum; interpretation of structures follows that of Besuchet, 1957 and Zaragoza Caballero, 1991. Figs 26-30 redrawn from Zaragoza Caballero, 1991.

and one small fly and one wasp. Paratype 6. No. SMNS-Do5735 (JBAC DA02/DR4065), male, Dominican amber. Original size of amber piece was $29 \times 31 \mathrm{~mm}$. Location: La Cumbre group of mines. In the same piece of amber there are three winged termites and some small wasps (in coll. Muséum National d'Histoire Naturelle, Paris, A. Nel). Paratype 7. No. SMNS-Do-5739 (JBAC DA09/4/4), male, Dominican amber. Exoskeleton is poorly preserved.

Etymology. The specific epithet is a matronym honoring Ms. Elizabeth Luzzi, niece of Keith Luzzi who generously donated the holotype specimen to the University of Kansas Natural History Museum.

Comments. Quasipirhidius luzziae sp. n. is similar to the extant Quasipirhidius besucheti Zaragoza Caballero, 1991 from Mexico by its enlarged compound eyes reaching nearly the posterior margin of the head in lateral aspect. The fossil species differs from it by the shape of the mesonotum, metaprescutum and metascutellum (see Figs 31-32). A white depression at the elytral apex is not mentioned in the generic diagnosis of Quasipirhidius but is present in some other ripidiine genera; although this feature cannot serve as a diagnostic character for the generic level.

\section{Genus Neorrhipidius Viana, 1958}

Neorrhipidius seicherti sp. $\mathbf{n}$.

(Figs 33-37)

\section{Diagnosis (male)}

As in Quasipirhidius luzziae sp. n. (vide supra) except as follows: two postocular ommatidia present on each side of the head (but see Comments), the widest part of metascutellum is $5.5 \times$ wider than its base contiguous to metaprescutum. Measurements in Table 1.

Female: Unknown.

Immature Stages and Host: Unknown.

Holotype. No. SMNS-Do-5734 (JBAC DA03/42), male, Dominican amber. Original size of amber piece was $6 \times 7 \mathrm{~mm}$. Paratype. No. SMNS-Do-5736 (JBAC DA04/1108-166), male, Dominican amber. Precise mines are not known.

Etymology. Dedicated to Professor Emeritus Václav Seichert (Charles University, Prague), a well known anatomist and keen collector of Cerambycidae.

Comments. The fossil species is similar to the extant Neorrhipidius dureti Viana, 1958 from Paraguay in which also two postocular ommatidia are present, while other congeners have one or four postocular ommatidia. The apparent absence of both postocular ommatidia on the left 
side of the head in the holotype of $N$. seicherti sp. n. (Figs 34-35) is here interpreted as a teratological deviation of no taxonomic value. The shape of the metascutellum in Neorrhipidius seicherti sp. n. (Fig. 33) is similar to that in N. cordobensis Viana, 1958 (Fig. 24) whereas the same structure in Quasipirhidius luzziae sp. n. (Figs 31-32) is similar to that in Q. rieki Zaragoza Caballero, 1991 (Fig. 30).

\section{DISCUSSION}

\section{Distribution of extant Ripidiinae in Central America}

The fauna of Ripidiinae in Central America is poorly documented. However, both currently recognized tribes of the subfamily (i.e., Eorhipidiini and Ripidiini) are known in the region. At least four native genera of Ripidiini have been recorded in Central America and along the Gulf of Mexico (Zaragoza Caballero, 1984, 1991; Falin, 2001; Batelka, unpublished; for summary see Table 2) and undescribed taxa of the tribe Eorhipidiini from Central America (Belize, Mexico) are also known (M. Barclay, pers. comm.; Falin, unpublished). No extant representatives of Ripidiinae have been reported from the West Indies.

\section{Fossil Ripidiini recorded in Dominican amber}

Abundance. Individuals of Ripidiini are remarkably abundant in Dominican amber in comparison with other amber deposits (cf. Kaupp et al., 2001). As previously mentioned, one specimen was figured in Poinar \& Poinar (1999: photo 152), and one specimen and a triple syninclusion were depicted in Wu (1997: F-386, F-436 and F-437). A further male is deposited in Joachim Scheven's collection (Germany) (Scheven, 2006) and four additional specimens (one double syninclusion and two single specimens) were available for sale in 2008-2010 through E-Bay under items 'A101 DR7952 Super Rare Ripiphorids in Dominican Amber', 'DR4326 a Superb Beautiful Super Rare Ripiphorid' and 'A101 DR9478 Super Rare Ripiphorid in Dominican Amber' (archive of the first author). Judging from the available microphotographs, all 10 of these males could belong to Quasipirhidius luzziae sp. n. The male ripiphorid figured in Grimaldi \& Engel (2005: Fig. 10.57.) is likely Neorrhipidius seicherti sp. n. owing to two postocular ommatidia. No ripiphorid inclusion is presently known in Mexican amber, also of Early Miocene age. It seems probable that currently there are more than 20 males of Quasipirhidius luzziae sp. n. in
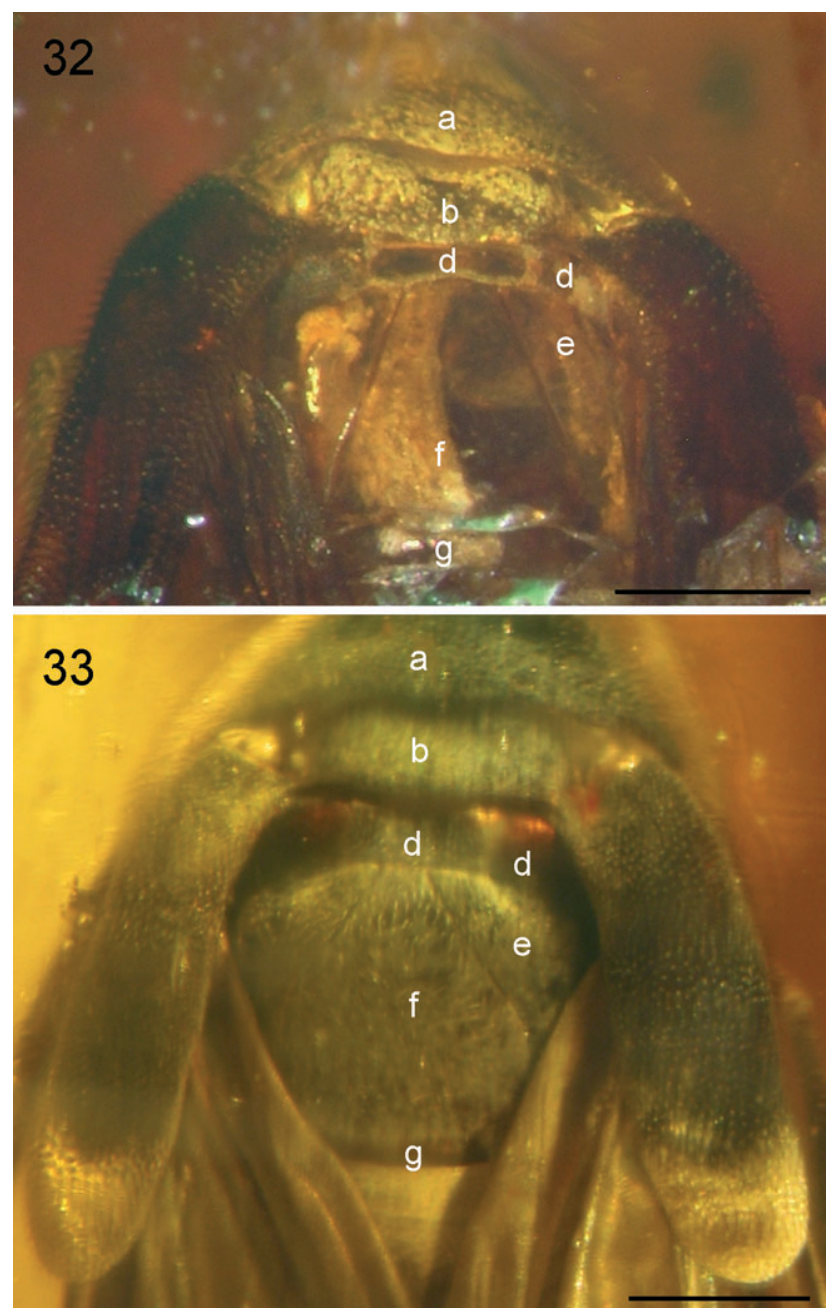

Figs 32-33. Pronotal disc, mesonotal disc and metanotum. 32 - Quasipirhidius luzziae sp. n. paratype 5 No. DA08/01491 (scale bar $0.5 \mathrm{~mm}$ ); 33 - Neorrhipidius seicherti sp. n. paratype No. DA04/1108-166 (scale bar 0.8 mm).

private and public collections worldwide, interestingly more than are typically available for many of its extant relatives.

Paleoethology. Several double and triple syninclusions of Quasipirhidius luzziae sp. n. and the relatively common presence of this species in Dominican amber may shed light on the paleoethology of this species and possibly on the behaviour of Ripidiini in general. Adult Ripidiini possess atrophied mouthparts which are not suit-

TABLE 2. Distribution of extant Ripidiini in Central America and the Gulf of Mexico.

\begin{tabular}{lll}
\hline Genus & Species & Distribution \\
\hline Pirhidius Besuchet, 1957 & Pirhidius undescribed species (Falin, 2001) & Florida (U.S.A.) \\
Quasirhipidius Zaragoza Caballero, 1991 & Quasirhipidius selanderi Zaragoza Caballero, 1991 & Mexico \\
Quasipirhidius Zaragoza Caballero, 1991 & Quasipirhidius besucheti Zaragoza Caballero, 1991 & Mexico \\
& Quasipirhidius rieki Zaragoza Caballero, 1991 & Mexico \\
& Quasipirhidius undescribed species (JB det. and coll.) & Panama \\
Ripidius Thunberg, 1806 & Ripidius mexicanus Zaragoza Caballero, 1984 & Mexico \\
& Ripidius pectinicornis Thunberg, 1806, introduced (Falin, 2001) & on ships \\
unidentified & 1 ex. in coll. Naturhistorisches Museum, Basel, examined by JB & Costa-Rica \\
\hline
\end{tabular}




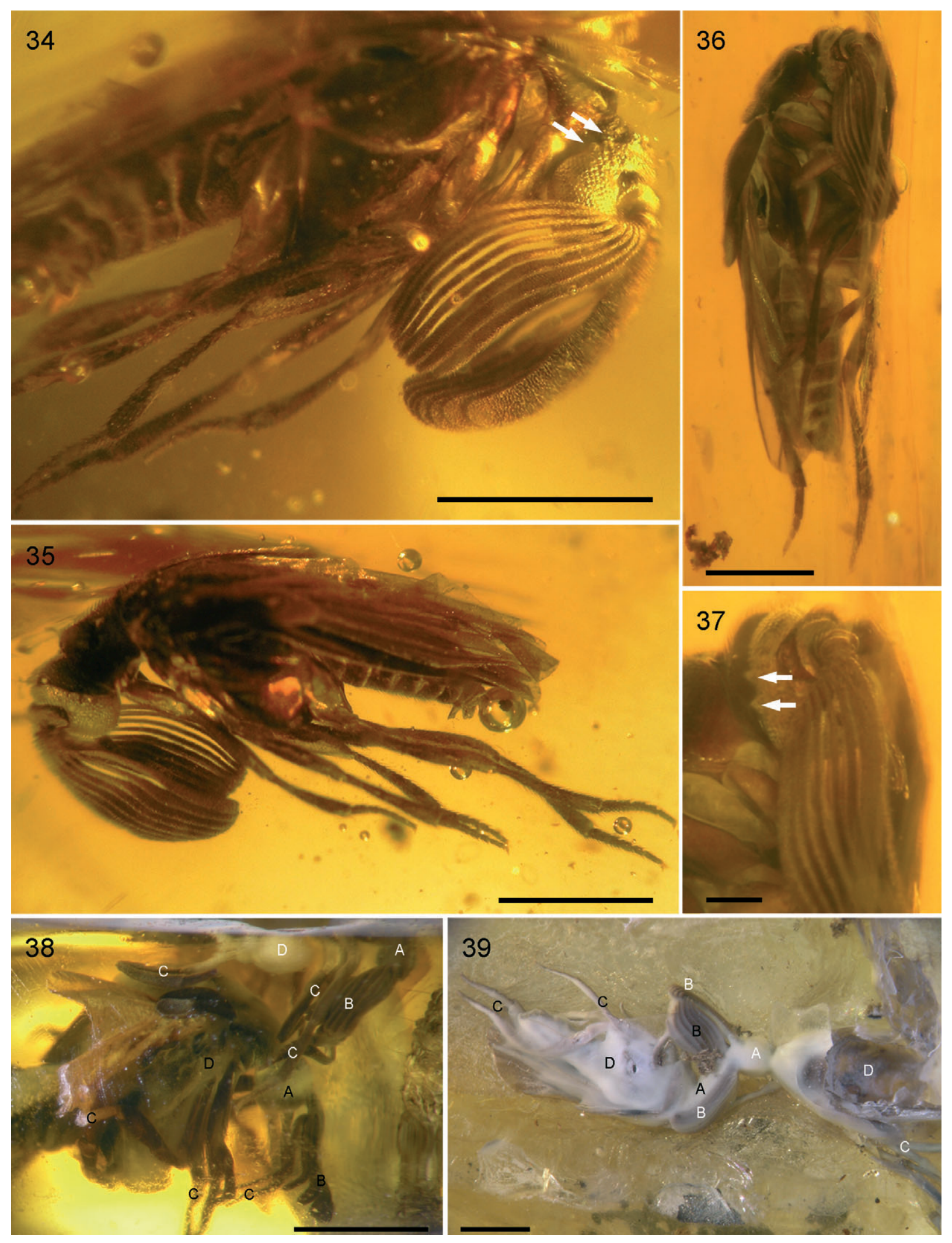

Figs 34-39. 34-35, Neorrhipidius seicherti sp. n. holotype No. DA03/42: 34 - right side (arrows to postocular ommatidia); 35 left side. 36-37, Neorrhipidius seicherti sp. n. paratype specimen No. DA04/1108-16636: 36 - habitus; 37 - detail of head (arrows to postocular ommatidia). 38 - Pauroripidius groehni Kaupp \& Nagel, 2001 (Baltic amber), specimen No. JBAC BaA02, double conspecific syninclusion (males), one complete specimen, remnants of the second male are visible above [head (A), antennae (B), legs (C) and milky thorax (D) are preserved]. 39 - Ripidius sp. (Baltic amber), specimen No. JBAC BaA03, triple conspecific syninclusion (males), first and second specimen in detail [heads (A), antennae (B), legs (C) and thoracic segments (D)]. The second incomplete specimen (right) was damaged by grinding. Eight-segmented flabellum characteristic for this genus is distinguishable in both specimens under binocular; fragments of the third specimen (e.g., elytron with characteristic whitish tip, hind wing, apex of abdomen, and middle and hind legs) not figured. Figs 34-36, 38-39: scale bars $1 \mathrm{~mm}$; Fig. 37: scale bar $0.2 \mathrm{~mm}$. 
able for ingesting or imbibing materials (e.g., from flowers or plant fluids). Fresh Hymenaea resin in the ancient forest canopy was likely functionally identical with modern sticky or flight intercept traps used by entomologists. Flowing resin is not an attractant but can capture easily these beetles in flight whenever they happen to come into contact with its sticky surface, specifically ripidiine males while they are searching for females. For syninclusions, when two or more organisms are entombed in the same piece of amber, we can expect that they lived in the same place and even that they died on the same day (Arillo, 2007). Syninclusions of male specimens of Ripidiini preserved in Dominican and Baltic ambers thus may be explained as a result of intraspecific aggregative behaviour of these short-lived creatures. Females, where known, occur in the crevices of or under bark. Males therefore may have aggregated on surfaces where females were emerging, much as in many modern parasitoid wasps. Interestingly, numerous males aggregated around a single female of the extinct parasitoid wasp Electrostephanus janzeni Engel, 2005 (Hymenoptera: Stephanidae) likely resulted from a similar behavioral event (Engel, 2005). It is peculiar that ripidiine females are not known in amber given their (sub)cortical habitats which would have placed them in close proximity with resin flows. Naturally, some females, which are completely larviform, may have been discovered but reside in collections as unidentified beetle "larvae", not yet recognized as adult ripiphorids. Similar paleoethologies may have existed for two genera known from Baltic amber such as the double syninclusion of Pauroripidius groehni (SMNS-BB-2451: JBAC BaA02, Fig. 38) and the triple syninclusion of Ripidius sp. (?primordialis) (SMNS-BB2452: JBAC BaA03, Fig. 39). However, such aggregative behaviour documented in fossil Ripidiini has not been recorded either in their extant representatives or in any other fossil or extant members of Ripiphoridae.

The occurrence of male syninclusions could also result from possible synchronisation of male hatching and emergence, a phenomenon unknown among extant Ripidiini. Further study of the biology and behavior of modern Ripidiinae should also contribute to understanding the biology of the fossil species.

ACKNOWLEDGEMENTS. The first author (JB) is particularly indebted to V. Seichert for his introduction to the study of nature during the author's childhood in Sudan. We thank A. Nel (Paris) for preparation of amber pieces from the first author's collection, and Z. Čadová (scientific illustrator) for her magnificent line drawings. The fourth author (JP) acknowledges the research support from the Grant Agency of the Czech Republic No. 205/08/0643 and Ministry of Education MSM 0021620828. MSE and ZHF are indebted to K. Luzzi for his support and generous donation of amber fossil material to the University of Kansas and to NSF DEB-0542909 (to MSE) for support of their work.

\section{REFERENCES}

ArILLo A. 2007: Paleoethology: fossilized behaviour in amber. Geol. Acta 5: 159-166.
Arillo A. \& Ortuño V.M. 2005: Catalogue of fossil insect species described from Dominican amber (Miocene). Stuttg. Beitr. Naturkd. (B) 352: 1-68.

BatelKa J. 2009: Confirmation of the synonymy of Rhyzostylops with Blattivorus and the description of the male of Blattivorus inquirendus (Coleoptera: Ripiphoridae: Ripidiinae). Acta Entomol. Mus. Natn. Pragae 49: 247-251.

Batelka J. \& HÁJeK J. 2010: Taxonomy and distribution of the genus Pterydrias Reitter and confirmation of its synonymy with Eorhipidius Iablokoff-Khnzorian (Coleoptera: Ripiphoridae: Ripidiinae). Zootaxa 2566: 64-68.

Batelka J., Collomb F.-M. \& Nel A. 2006: Macrosiagon deuvei n. sp. (Coleoptera: Ripiphoridae) from the French Eocene amber. Ann. Soc. Entomol. Fr. (N.S.) 42: 75-78.

Besuchet C. 1957: Contribution à l'étude des Rhipidiinae (Col. Rhipiphoridae). Bull. Soc. Vaudoise Sci. Nat. 66: 341-351.

Cockerell T.D.A. 1917: Fossil insects. Ann. Entomol. Soc. Am. 10: $1-22$.

ENGEL M.S. 2005: The crown wasp genus Electrostephanus (Hymenoptera: Stephanidae): Discovery of the female and a new species. Pol. Pis. Entomol. 74: 317-332.

FALIN Z.H. 2001: Notes on occurrence of Ripidius pectinicornis Thunberg (Coleoptera: Rhipiphoridae) in the continental United States and Hawaii. Coleopt. Bull. 55: 194-197.

FALIN Z.H. \& Engel M.S. 2010: Notes on Cretaceous Ripidiini and revised diagnoses of the Ripidiinae, Ripidiini, and Eorhipidiini (Coleoptera: Ripiphoridae). Alavesia 3: 35-42.

GRIMALDI D. 1995: The age of Dominican amber. In Anderson K.B. \& Crelling J.C. (eds): Amber, Resinite, and Fossil Resins. American Chemical Society, Washington, D.C., pp. 203-217.

Grimaldi D. 1996: Amber: Window to the Past. H.N. Abrams, New York, 216 pp.

Grimaldi D.A. \& Engel M.S. 2005: Evolution of the Insects. Cambridge University Press, New York, xv +755 pp.

IturRalde-Vinent M.A. \& MacPhee R.D.E. 1996: Age and paleogeographical origin of Dominican amber. Science 273: $1850-1852$.

Iturralde-Vinent M.A. \& MacPhee R.D.E. 1999: Paleogeography of the Caribbean region: Implications for Cenozoic biogeography. Bull. Am. Mus. Nat. Hist. 238: 1-95.

Kaupp A., Falin Z. \& Nagel P. 2001: An annotated catalogue of fossil Ripiphoridae, taxonomic notes, and the description of a new genus and species from Baltic amber (Coleoptera: Ripiphoridae: Ripidiinae). Mitt. Geol.-Paläontol. Inst. Univ. Hamburg 85: 165-195.

Lambert J.B., Frye J.S. \& Poinar G.O. 1985: Amber from the Dominican Republic: Analysis of nuclear magnetic resonance spectroscopy. Archaeometry 27: 43-51.

Perrichot V., Nel A. \& Neraudeau D. 2004: Two new wedgeshaped beetles in Albo-Cenomanian ambers of France (Coleoptera: Ripiphoridae: Ripiphorinae). Eur. J. Entomol. 101: 577-581.

PoINAR G.O. 1992: Life in Amber. Stanford University Press, Stanford, $350 \mathrm{pp}$.

Poinar G.O. \& Polnar R. 1999: The Amber Forest: A Reconstruction of a Vanished World. Princeton University Press, Princeton, NJ, xviii + 239 pp.

PoINAR G.O. JR. 2001: Dominican Amber. In Briggs D.E.G. \& Growther P.R. (eds): Palaeobiology II. Blackwell Science, Oxford, London, Edinburgh, pp. 362-364.

SCHEVEN J. 2006: Käfer in dominikanischem Bernstein. $<$ http://www.koleopterologie.de/gallery/EXTRA/bernstein/ dominikanisch-index.html $>$ (Accessed 25 October 2006.)

Viana M.J. 1958: Neorrhipidius, nuevo género perteneciente a la tribu Rhipidiini, con tres nuevas especies de Argentina y 
Paraguay (Coleoptera, Rhipiphoridae). Bol. Mus. Argentino Cienc. Nat. "Bernardino Rivadavia" 15: 1-26.

Wu R.J.C. 1997: Secrets of the Lost World: Dominican Amber and its Inclusions. By the author, Santo Domingo, $222 \mathrm{pp}$.

Zaragoza Caballero S. 1984: Una nueva especie de Rhipidius Thunberg, 1806 (Coleoptera: Rhipiphoridae: Rhipidiinae) de
México. An. Inst. Biol. Univ. Nac. Auton. Mexico (Zool.) 54[1983]: 105-110.

Zaragoza Caballero S. 1991: Nuevos Rhipidiinae de México (Coleoptera: Rhipiphoridae). An. Inst. Biol. Univ. Nac. Auton. Mexico (Zool.) 62: 481-495.

Received April 19, 2010; revised and accepted December 21, 2010 